\title{
O financiamento das pequenas empresas e o desequilibrio territorial rural-urbano: 0 caso da provincia da Coruña
}

\author{
The financing of small enterprises and the rural-urban \\ divide: the case of the province of A Coruña \\ DAVID PEÓN POSE \\ Departamento de Empresa. Universidade da Coruña \\ ORCID 0 000-0002-5212-4385 \\ davidpeon@gmail.com \\ XOSE MANUEL MARTÍNEZ FILGUEIRA \\ Departamento de Economía. Universidade da Coruña \\ noia@udc.gal
}

\section{RESUMo}

Tras a crise financeira, a reordenación do mapa bancario e consecuente perda de entidades financeiras propias, cuestionámonos se a problemática de acceso a crédito bancario pode ser máis acusada para as PEMEs galegas en entornas rurais. O obxectivo da investigación é o estudo do crédito comercial como alternativa ao crédito bancario, o diagnóstico das dificultades de acceso a financiamento e a súa relación cos desequilibrios territoriais rural-urbano.

Os resultados son aínda preliminares, pola necesidade de refinar os datos de acceso a financiamento das empresas e as escollas de tipo econométrico. Con todo, tomando unha mostra de empresas industriais da provincia da Coruña, compróbase que os volumes de crédito comercial son relativamente baixos no contexto europeo, e as empresas que operan no rural conceden menos crédito comercial que as urbanas. Ademais, fináncianse máis vía provedores - coherente coa hipótese de contar con peor acceso a crédito bancario - mais o efecto non é significativo para as empresas independentes.

Palabras chave: financiamento empresarial, crédito comercial, desenvolvemento rural, PEMEs

\footnotetext{
Abstract

After the worldwide financial crisis and the restructuring of the banking industry, we wonder whether bank credit constraints are more relevant today for Galician SMEs in rural areas. The objective of our research is the study of trade credit as an alternative to bank credit, the difficulties to get bank financing, and its relationship with rural-urban territorial imbalances.
} 
The results are preliminary, both because of data available and econometric choices. Nonetheless, using a sample of industrial companies in the province of A Coruna, we observe that the volumes of trade credit are relatively low in the European context. Firms that operate in rural municipalities grant less trade credit than urban ones, while they finance more via suppliers - consistent with the hypothesis of bank credit constraingts - though the effect is not significant for independent businesses.

Keywords: corporate finance, trade credit, rural development, SMEs.

\section{INTRODUCIÓN}

As desigualdades territoriais dificultan o desenvolvemento e cohesión rexionais, agravadas polo envellecemento e as peores perspectivas demográficas que a miúdo caracterizan ás zonas rurais. As políticas públicas procuran por iso incidir nos factores que explican o mellor comportamento dalgunhas rexións. No ámbito empresarial, as PEMEs son un obxectivo chave na estratexia Europa 2020, orientada a promover condicións de competencia equitativas nas que as empresas, con independencia do tamaño, teñan as mesmas posibilidades de éxito. As políticas de desenvolvemento rural avogan por fomentar o emprendemento con enfoques multisectoriais, as integracións horizontais e verticais, a innovación, a creación de redes e a cooperación entre os empresarios (Cork, 2016). Porén, as PEMEs rurais deben facer fronte a problemáticas de seu, como ter que desenvolver as súas actividades en ecosistemas menos favorables, a capacidade de xestión da innovación, ou os problemas de acceso a financiamento.

É neste último aspecto no que se centra este artigo. A dificultade de acceso ao crédito é un factor determinante na competitividade empresarial das PEMEs rurais. O marco conceptual de referencia identifica o crédito comercial -operación na que un provedor ofrece condicións que permiten ao seu cliente retrasar o pagamento do ben ou servizo adquirido- como substituto do financiamento bancario. En particular, nun contexto de restrición de crédito, unha empresa que non pode conseguir dos bancos todo o financiamento preciso, é probable que recorra a fontes alternativas, coma o crédito comercial (Danielson e Scott, 2004). O efecto substitución sería máis patente de cumprirse a "hipótese da fuxida á calidade", segundo a cal, en tempos de crise, o crédito fuxe das pequenas empresas máis necesitadas de financiamento, cara ás máis grandes ou con posicións máis solventes (Psillaki e Eleftheriou, 2015; McGuinness e Hogan, 2016).

Contribuímos á literatura co caso de Galicia, centrado no contexto posterior á crise financeira, e con especial énfase na interpretación territorial dos resultados. O caso galego é de especial relevancia por dúas cuestións. Primeira, Galicia é un exemplo paradigmático a nivel europeo de rexión envellecida en recesión demográfica, resultado das fortes migracións nos anos 1950-1975. O estudo do impacto territorial rural-urbano na literatura sobre crédito comercial non é novidoso (e.g., Niskanen e Niskanen, 2006), pero tampouco extensa nin concluínte. Máis aínda, a liña de investigación principal céntrase na análise de economías rurais en países en desenvolvemento, pero poucas interpretan a dualidade 
rural-urbana en rexións de Europa, e ningún artigo de referencia fai fincapé en contextos de estancamento demográfico.

O segundo aspecto relevante do caso galego é o forte impacto da crise financeira no tecido empresarial e, en particular, no sector bancario. Na década de 2010, alén da quebra de empresas de referencia como Pescanova ou Fadesa, desaparecen as principais entidades financeiras do país: as caixas de aforro Caixanova e Caixa Galicia, e a principal entidade bancaria, Banco Pastor. A reordenación do mapa bancario e consecuente perda de capacidade de decisión, a menor capilaridade da rede comercial, e a desaparición das caixas de aforro cunha orientación máis social, poderían danar, a priori, máis ás empresas de entornas rurais galegas. Sexa como for, a literatura identifica unha relación entre o número de entidades bancarias presentes a nivel local e o recurso ao financiamento vía crédito comercial por parte das empresas, polo que o estudo do caso galego nos últimos anos amósase especialmente interesante.

No presente traballo cuestionámonos se a problemática de acceso a financiamento pode ser máis acusada para as PEMEs galegas en entornas rurais: o obxecto de estudo é o crédito comercial concedido e recibido por pequenas empresas (PEs) de sectores industriais, o diagnóstico das dificultades de acceso a financiamento e a súa relación cos desequilibrios territoriais rural-urbano. O artigo contribúe en dúas direccións. Primeira, a partir dunha mostra coas preto de 1.000 empresas da provincia da Coruña con entre 5 e 50 empregados e información financeira completa na base de datos SABI, operando en calquera dos sectores industriais e construción da CNAE, realizamos unha análise descritiva comparativa do acceso a financiamento bancario, o seu custe, e o recurso ao crédito comercial, das PEs en concellos rurais fronte ao resto. Segunda, aplicando a metodoloxía de datos de panel, analízanse os principais determinantes do crédito comercial concedido e recibido nos anos 2012-2016, ao obxecto de identificar diferenzas significativas para empresas operando en entornas rurais. Para a clasificación de empresa operando en contornas rurais, intermedias ou urbanas, relaciónase cada empresa co concello de domicilio social, e este coa clasificación IGE conforme a metodoloxía DEGURBA.

A estrutura do artigo é a seguinte. Tras unha breve introdución de Galicia e o sector empresarial industrial da provincia da Coruña como caso de estudo, revísase a literatura de factores determinantes do crédito comercial. Na Sección 4 descríbese a mostra e variables, e realízase unha análise descritiva dos datos. Na Sección 5 preséntase a metodoloxía e resultados da análise con datos de panel. Por último, conclúese con algunhas reflexións sobre o alcance e limitación dos resultados na Sección 6.

\section{CASO DE ESTUDO: GALICIA}

Galicia, afronta un escenario demográfico nas vindeiras décadas cando menos preocupante. É un caso paradigmático en Europa, de maior gravidade que calquera dos países do entorno, manifestado nunha baixa natalidade e elevado envellecemento, altos 
niveis de dependencia, a perspectiva dunha forte perda poboacional nas vindeiras décadas, e grandes desigualdades territoriais no acceso a emprego e servizos, en particular nos concellos rurais. A polaridade rural-urbana e a dinámica recesiva das zonas rurais é aínda máis acusada. O devalo demográfico e socioeconómico do rural, a súa supervivencia tal e como a entendíamos ata agora, é un reto que debe afrontar a sociedade galega. Hoxendía, case o $70 \%$ da poboación vive no $15 \%$ do territorio, o Eixo Atlántico (ver Figura 1).
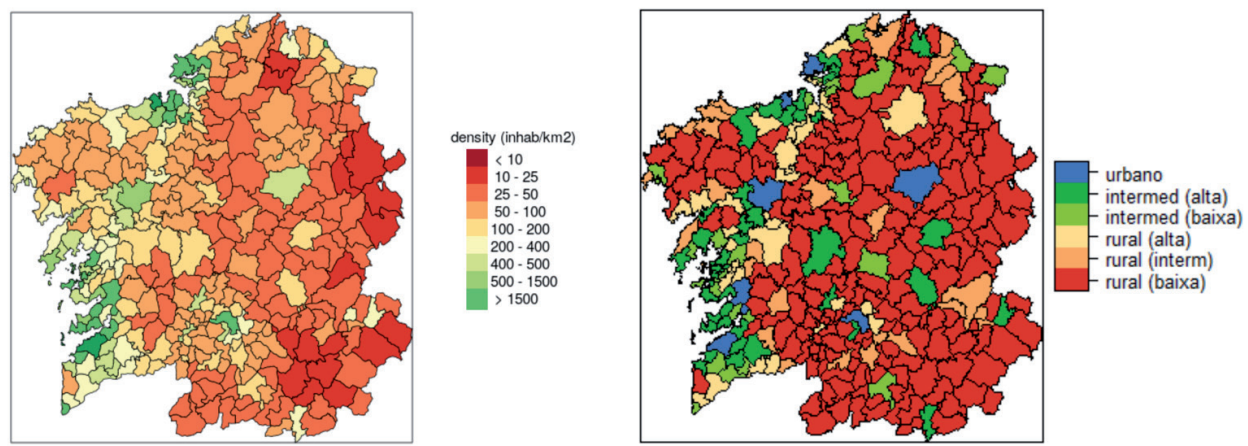

Figura 1. Distribución territorial da poboación galega

Densidade por concellos 2011 e tipoloxía rural-urbana (DEGURBA)

Fonte: Elaboración propia. Datos: INE, Censo 2011; IGE (2016)

A orixe deste comportamento ten raíz económica: Galicia leva décadas por detrás de España en termos de crecemento demográfico e PIB, perdendo peso relativo de xeito persistente. No rural en particular, desde mediados do século XX prodúcese un descenso abrupto do emprego no sector agrícola, non compensado por creación de emprego noutros sectores, o que levou a fortes migracións do rural ao urbano nos anos 60 e 70 do século pasado. O Plan para a dinamización demográfica de Galicia 2013 - 2016 apunta ao fomento da natalidade como eixo principal, pero esa é xa unha solución tardía para corrixir a estrutura de poboación das comarcas do rural e interior de Galicia (López Iglesias, 2013). A inercia demográfica dunha poboación envellecida leva a que a perda poboacional persista no tempo ata hoxe en moitos concellos do rural galego.

Entre as posibles solucións que algúns autores formulan, serían necesarias políticas adicionais de tipo socioeconómico (emprego, servizos) e de ordenación do territorio (Fernández e Peón, 2017). O apoio ao emprendemento e desenvolvemento empresarial das PEMEs é un obxectivo central da estratexia Europa 2020 e, en particular, nas zonas rurais. En España representan o $99.8 \%$ das empresas, sendo as micro empresas con menos de 10 traballadores o $95.8 \%$ (o $92.4 \%$ na UE), e ocupando ao $66.0 \%$ dos traballadores, dato similar á media europea. ${ }^{1}$ Porén, a capacidade destas empresas para contribuír a reverter o devalo

1 Fonte:CEPYME (http://www.cepyme.es/1344-las-pymes-protagonistas-del-crecimiento-y-del-empleo/). Acceso Abril 2018. 
do rural é limitada -en particular, a de aquelas que operan baixo un enfoque de 'economía residencial' (Barbut, 2009), dependente da capacidade de consumo de residentes e turistas. Con altos niveis de despoboamento e envellecemento, as expectativas de crecemento demográfico negativas amenizan con marxinar boa parte dos concellos rurais no futuro.

O presente artigo céntrase, pois, no estudo de empresas de varios sectores industriais conforme a clasificación CNAE, máis orientadas a un enfoque de 'economía produtiva', menos dependente da capacidade de consumo local. A razón desta escolla débese á importancia que o crédito comercial xoga na relación provedor - cliente en empresas deste tipo. Conforme aos datos do Instituto Galego de Estatística (IGE), o total de empresas rexistradas con actividade en sectores industriais na provincia da Coruña no ano 2012. Dun total de case 20,000 empresas, o $81.0 \%$ teñen 0 a 2 traballadores e máis do $90 \%$ son pequenas empresas con menos de 10 empregados. Dous terzos delas concéntranse nos sectores de construción especializada e construción, e entre as empresas industriais destacan por número de empresas as industrias de alimentación, confección de roupa, madeira, fabricación de produtos metálicos, fabricación de mobles e reparación de maquinaria.

\section{FACTORES DETERMINANTES DO CRÉDITO COMERCIAL: ESTADO DA ARTE}

O crédito comercial é a posibilidade que os provedores ofrecen para recibir hoxe a mercadoría ou provisión do servizo, e adiar un tempo o pagamento efectivo do importe debido. Para o provedor representa un investimento en clientes, no epígrafe de 'debedores comerciais e outras contas a cobrar', mentres que para o cliente é unha vía de financiamento que figurará en balance no epígrafe de 'acredores comerciais e outras contas a pagar' (García-Teruel e Martínez-Solano, 2010). Para moitas empresas representa unha vía de financiamento habitual: pode actuar como substituto ou como complemento ao financiamento bancario, mais nun contexto de forte restrición crediticia como a experimentada tras a crise e reestruturación bancaria en España na última década, o seu papel substitutivo cobra relevancia.

Varios estudos empíricos recentes mostran como, nun contexto de restrición de financiamento bancario, as empresas con posicións de liquidez suficiente actúan como financiadores doutras máis necesitadas (Garcia-Appendini e Montoriol-Garriga, 2013; Psillaki e Eleftheriou, 2015; McGuinness e Hogan, 2016). Non está tan estudada, en cambio, a relación entre o crédito comercial e o ámbito rural ou urbano onde operan as empresas - e os resultados non son concluíntes. A literatura temperá apunta un maior uso das contas a cobrar e pagar en ámbitos urbanos, porque as empresas rurais terían menores restricións de crédito ao haber máis información dispoñible sobre os pequenos negocios e os seus xestores, e a presión para pagar as débedas ser maior (Petersen e Rajan, 1995). Porén, Harhoff e Körting (1998) identifican que as empresas de Alemaña Oriental soportan un custo do financiamento bancario un $0.9 \%$ superior ao de empresas comparables de Alemaña Occidental. 
Na literatura máis recente, a liña de análise máis extensa en relación ao rural é a que analiza as condicións de financiamento das pequenas empresas en países en desenvolvemento. En China, Yano e Shiraishi (2011) comproban que o financiamento vía crédito comercial é máis eficiente que o bancario, e Sun e Hu (2013) mostran que o crédito comercial ten un efecto positivo sobre a produtividade empresarial. Na India hai unha vasta literatura sobre micro créditos e emprendemento, pero pouco sobre a alternativa que o crédito comercial supón para as PEMEs (e.g., Milder, 2008). Algúns destes artigos analizan diferenzas étnicas ou entre provincias, pero non tanto as diferenzas rural - urbano nun contexto onde ademais o sistema bancario apenas está desenvolvido. Referido a economías desenvolvidas, Gustafson (2005) observa que as PEMEs do rural norte-americano con maior uso de sistemas informáticos de xestión de tesouraría e crédito actúan de prestamistas nas relacións de crédito comercial. Niskanen e Niskanen (2006) observan que as empresas nas zonas urbanas de Finlandia ofrecen e utilizan máis crédito comercial que as de entornas rurais. Por último, en Italia, Cassia e Vismara (2009) comproban que as empresas tenden a financiarse vía provedores cando as condicións de crédito bancario non son boas - o cal relacionan cun menor nivel de desenvolvemento da banca local - mais Deloof e La Rocca (2014) obteñen resultados contrarios: a maior desenvolvemento da banca local, aumenta a redistribución de préstamos vía maior oferta de crédito comercial.

\subsection{Factores determinantes da concesión de crédito comercial}

Por que empresas non financeiras ofrecen financiamento aos seus clientes de xeito frecuente? Os primeiros modelos teóricos xa apuntaban á existencia de restricións de crédito bancario para as empresas financiadas (Schwartz, 1974), fundamentadas na existencia de asimetrías de información (Biais e Gollier, 1997). Na actualidade, a literatura académica ofrece diversas razóns polas que os provedores ofrecen crédito comercial aos seus clientes, que podemos sintetizar en motivos de catro tipos: comerciais, operativos, financeiros, e de acceso a crédito.

Os motivos comerciais teñen dúas orixes. Primeira, se existen asimetrías de información entre compradores e vendedores, o crédito comercial permite aos provedores garantir a calidade dos seus produtos (Smith, 1987). De xeito recíproco, os provedores conseguen información sobre a capacidade crediticia dos seus clientes (Pike et al., 2005). Segunda, a teoría de discriminación de prezos (Petersen e Rajan, 1997) sinala que o crédito comercial permite aos provedores cobrar un prezo superior aos clientes de peor solvencia. A evidencia empírica mostra que as empresas con maior marxe comercial (diferenza entre o custo do ben ou servizo que ofrecen e o prezo que repercuten ao cliente) son as que máis teñen que gañar de incrementar as súas vendas e, polo tanto, as que máis crédito comercial ofrecerían por discriminación de prezos.

Os motivos operativos fundaméntanse na consecución de maiores niveis de eficiencia de negocio e redución de custos. O uso de crédito comercial reduce a incerteza de cobramentos e pagamentos (Ferris, 1981) e proporciona ás empresas maior flexibilidade 
para responder a variacións na demanda (Emery, 1987). Este enfoque tradúcese en varias predicións. Primeira, as posibilidades de crecemento do negocio poden influír nun sentido ou noutro á hora de conceder crédito a clientes: de xeito positivo, cando a empresa pretende medrar máis rápido, e ofrece mellores condicións de crédito comercial aos seus clientes que a competencia; ou de xeito negativo, cando o crecemento da demanda é baixo ou negativo poden ofrecer crédito comercial para mellorar o seu ritmo de vendas (Niskanen e Niskanen, 2006). Segunda, a existencia de economías de escala pode influír na concesión de crédito: neste sentido, a predición sería que as empresas de maior tamaño ofrecerían máis crédito ( $\mathrm{Ng}$ et al., 1999). Por último, o distinto poder de negociación entre clientes e provedores (Porter, 1979) influiría nos prazos e condicións do crédito comercial concedido.

A motivación financeira é a primeira apuntada na literatura académica. A teoría da liquidez e o crédito (Schwartz, 1974) suxire sinxelamente que o crédito comercial é o mecanismo polo cal as empresas que poden acceder a financiamento sen restricións e a baixo custo ofrecerán crédito máis gravoso a aquelas con limitacións financeiras. A motivación financeira está ligada, en primeiro lugar, coa existencia de asimetrías de información antes mencionadas, pero neste caso desde o punto de vista das entidades financeiras: os provedores contarían cunha vantaxe comparativa respecto dos bancos á hora de conseguir e monitorizar información sobre os seus clientes. E, en segundo lugar, a motivación financeira estaría ligada, tamén, coa solvencia e acceso a fontes de financiamento por parte de provedores e clientes.

Respecto á accesibilidade ao crédito, en resumo, as empresas con mellor acceso a fontes de financiamento, tanto propias como alleas, estarían dispostas a ofrecer crédito aos seus clientes en condicións que lle beneficien. No caso das PEMEs, as fontes habituais de financiamento poden ser o autofinanciamento (vía beneficios retidos), e o financiamento bancario. Neste caso, no caso de non contar cunha observación directa - a concesión ou denegación dos préstamos e créditos bancarios solicitados - soen empregarse proxies como a idade e tamaño da empresa, na idea de que empresas máis grandes e maduras teñen acceso máis factible ao crédito bancario (García-Teruel e Martínez-Solano, 2010), o custo da débeda inferida a partir da información contable - gastos financeiros sobre pasivos excluído crédito comercial - ou información sobre a estrutura competitiva do mercado bancario (Niskanen e Niskanen, 2006).

\subsection{Factores adicionais determinantes da solicitude de crédito comercial}

As motivacións polas que unha empresa cliente solicita financiamento do seu provedor son en boa medida similares ás identificadas no epígrafe anterior, pero gañan relevancia as referidas ao motivos financeiro e de acceso a crédito (e.g., García-Teruel e Martínez-Solano, 2010b). No referido a motivo financeiro, á teoría da liquidez e o crédito se engaden dúas razóns adicionais. Por unha banda, as empresas deben xestionar as necesidades de capital corrente, equilibrando o vencemento dos seus pasivos e a liquidez 
dos seus activos, de xeito que o fluxo de caixa xerado polos activos permita atender os vencementos de acredores (Morris, 1976). Por outra, existe un efecto substitución entre a débeda a longo prazo e o financiamento vía crédito comercial.

Canto ao acceso a fontes de financiamento, dependerá da capacidade da empresa para xerar financiamento interno, e do acceso a financiamento bancario. Porén, a observación empírica da 'dispoñibilidade de préstamos bancarios' requiren o uso de enquisas. En ausencia desta información, ou complementándoa, son habituais o uso de proxies, como a idade e tamaño da empresa, o custo do crédito bancario ao que teñen acceso (cando o teñen) ou a estrutura competitiva do mercado bancario - medida polo número de bancos presentes no concello da empresa.

Aos motivos anteriores engádense condicionantes xeográficos (e.g., o contexto rural ou urbano xa mencionado) ou macroeconómicos - medido habitualmente có crecemento do PIB. A relación entre ciclo económico e crédito comercial non está clara: en recesión os saldos de contas a cobrar poden aumentar polo efecto substitutivo do menor crédito bancario concedido e pola demora nos pagamentos por parte dalgúns clientes, pero en expansión económica o volume de negocio das empresas - e por tanto o crédito comercial recibido e concedido - é previsible que aumente (Niskanen e Niskanen, 2006). Por último, unha limitación adicional deste tipo de estudos é non poder inferir, a partir unicamente de información contable, cal é o custo do crédito concedido polo provedor, ou a frecuencia con que as empresas cliente fan uso do desconto por pronto pagamento (DPP). Exemplos de estudos que conseguen esta información vía enquisas sobre o uso de DPPs inclúen Harhoff e Körting (1998) ou Niskanen e Niskanen (2006).

\section{MOSTRA E DATOS}

Co obxecto de realizar un estudo do crédito comercial concedido e recibido, o diagnóstico das dificultades de acceso a financiamento, e a relación cos desequilibrios territoriais rural-urbano, aplicando a metodoloxía de datos de panel, faise uso da información financeira empresarial facilitada en SABI - Bureau van Dijk database, para tomar unha mostra de PEs galegas sectores industriais. Céntrase a análise nestes sectores, como é habitual en moitos estudos, pola importancia do crédito comercial entre provedores e clientes a través da cadea de valor.

\subsection{Mostra}

Seleccionamos unha mostra coas empresas da provincia da Coruña con entre 5 e 50 empregados e información financeira completa na base de datos SABI para os anos 2012 a 2016, que operan nos sectores de Industria da alimentación e fabricación de bebidas (SECT1), Industrias téxtil, madeira e papel (SECT2), Industrias do metal, metalurxia, fabricación e reparación de maquinaria (SECT3), Construción de edificios (SECT4), e 
Enxeñaría civil e construción especializada (SECT5). ${ }^{2}$ A seguir, fíltrase a base de datos eliminando en primeira instancia as empresas que non conten con activos e ingresos positivos en todos os anos. Neste paso caen tamén dúas empresas atípicas cun volume de activos o triplo superior que a maior das empresas da mostra. Elimínanse ademais observacións correspondentes a valores extremos nas variables dependentes e en doce dos regresores definidos na seguinte sección, se ben a robustez dos resultados será contrastada finalmente facendo uso tamén dos datos sen eliminar outliers. Por último, dado que algúns dos regresores requiren estimar o crecemento entre anos consecutivos, na aplicación das regresións pérdese o ano 2012, co que o panel data consiste en observacións para os anos 2013 a 2016.

En total, resultan 1.069 empresas (o 5.8\% das empresas no IGE para estes sectores, pero o $65.5 \%$ das que contan con entre 5 e 50 empregados). Para a clasificación do entorno rural ou urbano no que opera cada empresa, relaciónase a empresa co concello do seu domicilio social, e este coa clasificación de concellos rurais, intermedios ou urbanos IGE (2016), a cal segue a metodoloxía DEGURBA de Eurostat. A Táboa 1 amosa que a mostra está equilibrada tanto a nivel sectorial (porcentaxes do $12.0 \%$ ao 34.6\%) como rexional $(26.5 \%$ das PEs operan nos concellos da Coruña, Santiago de Compostela e Ferrol, $28.9 \%$ en concellos rurais, e $44.9 \%$ en intermedios). Os datos amosan que os concellos urbanos contan cun menor peso no sector de industrias do téxtil, madeira e papel (SECT2) e maior peso no de construción especializada (SECT5), mentres os concellos rurais amosan a situación contraria en ambos sectores, e un infrapeso no sector de industrias do metal e maquinaria (SECT3).

Táboa 1. Distribución sectorial e rexional das empresas da mostra

\begin{tabular}{|c|c|c|c|c|c|c|c|c|}
\hline & \multicolumn{5}{|c|}{ SECTOR } & \multirow{2}{*}{$\begin{array}{l}\text { Número de } \\
\text { empresas }\end{array}$} \\
\hline & & & SECT1 & SECT2 & SECT3 & SECT4 & SECT5 & \\
\hline \multirow[t]{9}{*}{ DEGURBA } & Urbano & Número de empresas & 32 & 20 & 70 & 51 & 110 & 283 \\
\hline & & \% sobre DEGURBA & $11.3 \%$ & $7.1 \%$ & $24.7 \%$ & $18.0 \%$ & $38.9 \%$ & $\%$ do total \\
\hline & & $\%$ do total & $3.0 \%$ & $1.9 \%$ & $6.5 \%$ & $4.8 \%$ & $10.3 \%$ & $26.5 \%$ \\
\hline & Intermedio & Número de empresas & 57 & 56 & 118 & 87 & 159 & 477 \\
\hline & & $\%$ sobre DEGURBA & $11.9 \%$ & $11.7 \%$ & $24.7 \%$ & $18.2 \%$ & $33.3 \%$ & $\%$ do total \\
\hline & & $\%$ do total & $5.3 \%$ & $5.2 \%$ & $11.0 \%$ & $8.1 \%$ & $14.9 \%$ & $44.6 \%$ \\
\hline & Rural & Número de empresas & 39 & 54 & 60 & 55 & 101 & 309 \\
\hline & & $\%$ sobre DEGURBA & $12.6 \%$ & $17.5 \%$ & $19.4 \%$ & $17.8 \%$ & $32.7 \%$ & $\%$ do total \\
\hline & & $\%$ do total & $3.6 \%$ & $5.1 \%$ & $5.6 \%$ & $5.1 \%$ & $9.4 \%$ & $28.9 \%$ \\
\hline \multirow[t]{2}{*}{ Total } & & Número de empresas & 128 & 130 & 248 & 193 & 370 & 1069 \\
\hline & & $\%$ do total & $12.0 \%$ & $12.2 \%$ & $23.2 \%$ & $18.1 \%$ & $34.6 \%$ & \\
\hline
\end{tabular}

Fonte: Elaboración propia

2 Os códigos CNAE incluídos en cada categoría son os seguintes: SECT1: 10. industria da alimentación, 11. fabricación de bebidas. SECT2: 13. industria textil, 14. confección de prendas de vestir, 15. industria do coiro e calzado, 16. industria da madeira e corcho, 17. industria do papel. SECT3: 24. metalurxia, 25. fabricación de produtos metálicos, 26. fabricación de produtos informáticos, electrónicos e ópticos, 27. fabricación de material e equipo eléctrico, 28. fabricación de maquinaria e equipo, 29. fabricación de vehículos de motor, 30. fabricación de outro material de transporte, 31. fabricación de mobles, 32. outras industrias manufactureiras, 33. reparación e instalación de maquinaria e equipo. SECT4: 41. construción de edificios. SECT5: 42. enxeñería civil, 43. actividades de construción especializada. 


\subsection{Variables}

Realizamos unha selección das variables de estudo conforme á revisión de literatura realizada na Sección 3. A lista de variables, a súa definición, e estatísticos descritivos facilítanse na Táboa 2. A seguir describimos cada unha delas, agrupadas por categorías.

Variables dependentes. Ao obxecto de analizar tanto o crédito comercial concedido como o recibido, tómanse variables dependentes de dous tipos:

- Contas a cobrar (RECS). Definida como a ratio de contas a cobrar sobre os ingresos por vendas, mide a porcentaxe das vendas que unha empresa financia aos seus clientes. Canto maior RECS, maior financiamento concedido.

- Contas a pagar (PAYAS). A ratio de contas a pagar sobre o total de activos mide a porcentaxe dos activos que se financian vía provedores. A maior PAYAS, máis relevante é o crédito comercial na política de financiamento da empresa.

Capacidade crediticia. Incluímos nesta categoría regresores de tres tipos. Primeiro, como medidas de autofinanciamento tomamos a ratio de beneficio neto máis amortizacións sobre os ingresos por vendas (INTFINS), e a mesma ratio sobre activos (INTFINA). Empregaremos INTFINS para explicar as contas a pagar, pero INTFINA coas contas a cobrar, evitando a multicolinealidade de INTFINS con outros regresores medidos en relación ás vendas que empregaremos. Espérase unha relación positiva entre INTFINA e RECS e negativa entre INTFINS e PAYAS: a maior capacidade para xerar financiamento interno, máis crédito ofrecerán aos seus clientes, e menos necesidade terán de solicitar financiamento dos provedores.

Segundo, como proxy da capacidade crediticia empréganse habitualmente na literatura a idade (AGE), medida polo número de anos desde que a compañía foi fundada, e o tamaño medido polo logaritmo dos activos da empresa (logASSETS) - a efectos descritivos incluímos tamén os estatísticos para os ingresos, logREVEN). A priori, tamaño e idade terían relación positiva con RECS (as empresas con acceso a crédito bancario ofrecerían máis crédito comercial se poden beneficiarse del), e negativa con PAYAS -as empresas máis maduras usan menos crédito de provedores polas súas oportunidades de investimento relativamente menores, e por contar con fontes alternativas de financiamento.

A maiores, ante a ausencia de medidas directas de dispoñibilidade de crédito bancario, tomamos dous proxies. Por unha banda, a variable dummy crecemento da débeda (DGRD) toma valor 1 nos anos nos que a débeda a longo prazo da empresa aumenta. A interpretación é similar á de tamaño e idade, positiva con RECS e negativa con PAYAS. Porén, é unha medida limitada no seu obxectivo de medir o acceso a financiamento, xa que só funciona nunha dirección: se medrou a débeda sabemos que a empresa tivo acceso a novo financiamento, pero se DGRD $=0$ ignoramos se non precisaba crédito, ou si o precisaba, pero non o puido conseguir. Por outra banda, un segundo proxy empregado é o custo da débeda (KD), medida pola ratio de gastos financeiros sobre pasivo total menos acredores comerciais. Xa que crédito comercial e bancario son substitutivos, KD tería a priori relación positiva con PAYAS e negativa con RECS. 


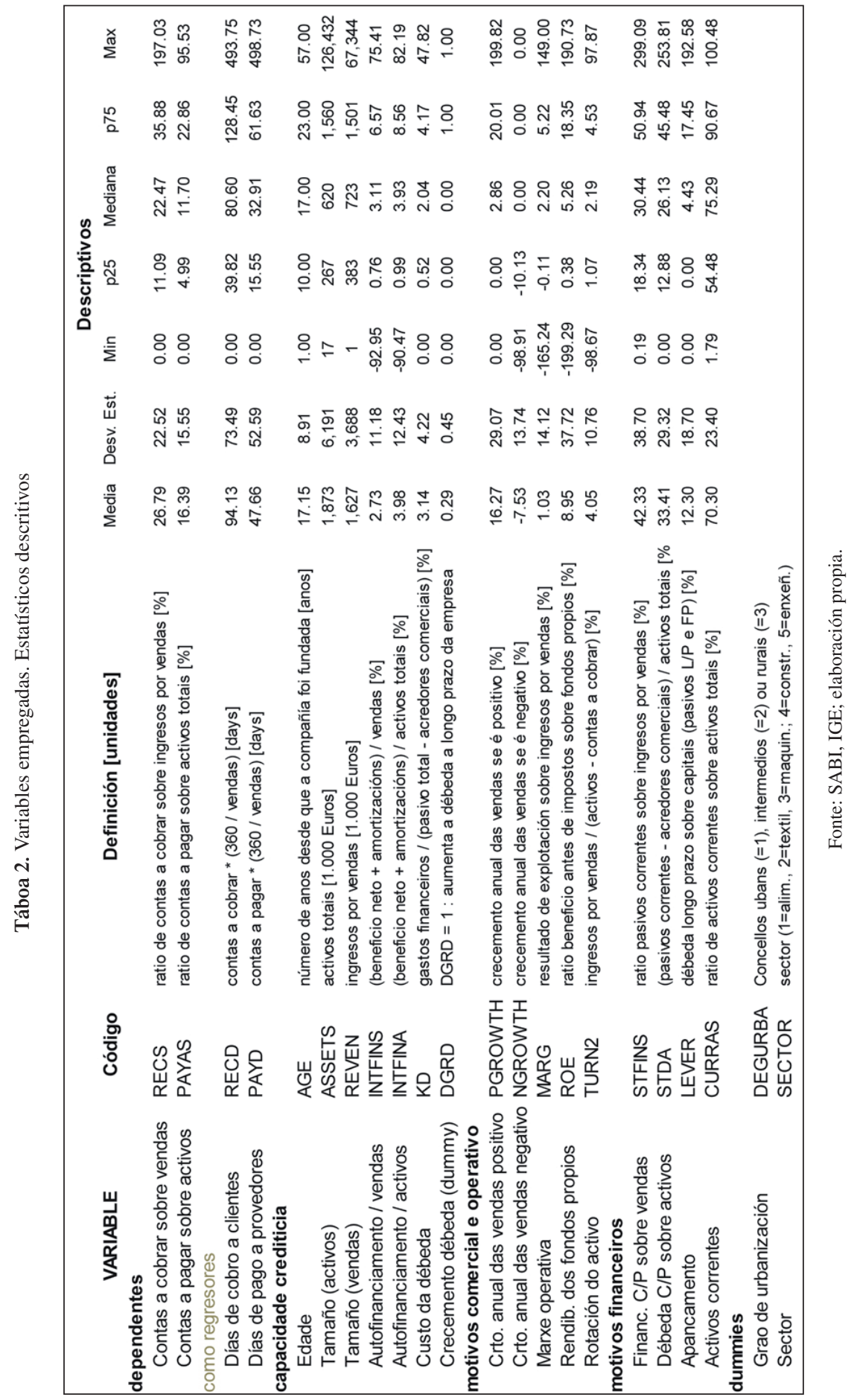


Motivos comercial e operativo. Incluímos regresores de catro tipos. Primeira, as oportunidades de crecemento do negocio medidas co crecemento anual das vendas se é positivo (PGROWTH) ou negativo (NGROWTH). Na literatura, o impacto sobre as contas a pagar é claro: a máis oportunidades de negocio máis necesidades de investir que necesitan ser financiadas, polo que PGROWTH (e NGROWTH, definida en termos negativos) terían relación positiva con PAYAS. A relación coas contas a cobrar dependerá da estratexia da empresa. Se unha empresa quere medrar máis rápido pode concederlle aos seus clientes prazos de pagamento maiores que os competidores, co que PGROWTH estaría positivamente ligado a RECS (a causalidade sería inversa). Porén, pode tamén ofrecer crédito como mecanismo comercial para mellorar datos pobres de vendas. Nese caso, PGROWTH e NGROWTH terían relación negativa con RECS.

Segundo, conforme a teoría de discriminación de prezos, as empresas con mais marxe comercial benefícianse ao cobrar prezos maiores a algúns clientes vía crédito comercial. Polo tanto, usamos a marxe operativa (MARG), definida como a ratio resultado de explotación sobre os ingresos por vendas. MARG estaría por tanto positivamente relacionada con RECS, e incluímos $\mathrm{MARG}^{2}$ para moderar o efecto das empresas con marxes elevadas (García-Teruel e Martínez-Solano, 2010). Comprobamos ademais se a rendibilidade para o accionista (ROE, medida có beneficio antes de impostos sobre fondos propios), puidera ter igual efecto sobre RECS. Terceiro, o crédito comercial permite reducir asimetrías de información garantindo a calidade do produto. Entón, a rotación do activo (TURN), definida como vendas sobre activos, estaría negativamente relacionada con RECS (a máis controis de calidade máis tempo require o ciclo de produción e venda). Porén, TURN introduce unha correlación ficticia con RECS por formar as contas a cobrar parte tamén do activo. Polo tanto, empregamos a medida modificada TURN2, ratio das vendas sobre activos, excluídas as contas a cobrar.

Por último, dado que coa información financeira dispoñible descoñecemos en que porcentaxes o crédito comercial ten custe ou non, o poder de negociación de clientes e provedores (Porter, 1979) afectaría aos casos nos que unha parte ou outra imporía condicións gratuítas ou gravosas. Para explicar RECS poderíamos incluír os prazo estimado de pago a provedores (PAYD), pero o seu carácter explicativo xa está recollido en MARG e STFINS. Para explicar PAYAS usamos o prazo estimado de cobro a clientes (RECD), medido polas contas a cobrar multiplicado por 360/vendas, así como o ROE (xa descrito). En ambos casos, a relación prevista é negativa.

Motivo financeiro. Incluímos regresores de tres tipos. Primeiro, definimos o financiamento a curto prazo (STFINS) como a ratio dos pasivos correntes sobre as vendas. Consonte a teoría da liquidez e o crédito pola que as empresas que conseguen financiamento bancario a baixo custo ofrecerán crédito comercial ás empresas con restricións, esperamos unha relación positiva entre STFINS e RECS. Para as contas a cobrar empregamos a débeda a curto prazo (STDA), ratio dos pasivos correntes menos acredores comerciais sobre activos totais. $\mathrm{O}$ efecto substitución entre crédito bancario a curto prazo e crédito 
comercial, normalmente con tipos de xuro efectivo superiores, fai que a relación agardada entre STDA e PAYAS sexa negativa.

Comprobamos tamén un efecto substitución entre débeda a longo prazo e crédito comercial coa variable apancamento (LEVER), definida como a ratio de pasivos de longo prazo sobre capitais (pasivos $\mathrm{L} / \mathrm{P}$ e fondos propios). Espérase unha relación negativa con PAYAS. Ademais, para explicar RECS incluímos LEVER coa seguinte hipótese: é posible que as empresas menos endebedadas teñan máis capacidade e interese en endebedarse para medrar. A relación con RECS sería positiva, pero non por motivo financeiro, senón comercial. Por último, as empresas precisan xestionar as súas necesidades de capital corrente, cadrando a liquidez dos seus activos coa esixibilidade das súas contas a pagar. Por tanto, para explicar PAYAS incluímos como medida de liquidez a ratio de activos correntes sobre activos totais (CURRAS), cunha relación esperada positiva con PAYAS.

\subsection{Estatística descritiva}

En primeiro lugar, canto ás variables explicadas crédito comercial concedido e recibido (Táboa 3), aprécianse diferenzas sectoriais relevantes no crédito concedido no sector alimentación vs. construción e enxeñería. As diferenzas no crédito recibido non son tan claras, só a menor concesión no sector téxtil. Canto ás diferenzas rural urbano, concédese menos crédito no rural, mentres que o recibido é similar.

As cifras son relativamente baixas en comparación có uso habitual de crédito comercial en países europeos (véxase García-Teruel e Martínez-Solano, 2010). Así, canto ás contas a cobrar, as medias para os sectores industriais galegos móvense máis na liña

Táboa 3. Crédito comercial concedido e recibido. Promedio 2013-2016, por sector e DEGURBA

\begin{tabular}{|c|c|c|c|c|c|c|}
\hline \multirow{2}{*}{ RECS } & \multicolumn{5}{|c|}{ SECTOR } & \multirow{2}{*}{$\begin{array}{l}\text { promedio } \\
\text { DEGURBA }\end{array}$} \\
\hline & 1 - Alim. & 2 - Textil & 3 - Maquin. & 4 - Constr. & 5 - Enxeñ. & \\
\hline \multirow{4}{*}{ 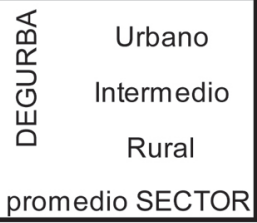 } & 11.23 & 29.62 & 29.32 & 30.71 & 31.59 & 28.44 \\
\hline & 13.76 & 19.59 & 29.57 & 30.06 & 29.68 & 26.64 \\
\hline & 9.34 & 19.03 & 23.38 & 32.49 & 32.59 & 25.53 \\
\hline & 11.80 & 20.77 & 28.01 & 30.93 & 31.03 & \\
\hline \multirow{2}{*}{ PAYAS } & \multicolumn{5}{|c|}{ SECTOR } & promedio \\
\hline & 1 - Alim. & 2 - Textil & 3 - Maquin. & 4 - Constr. & 5 - Enxeñ. & DEGURBA \\
\hline \multirow{4}{*}{ 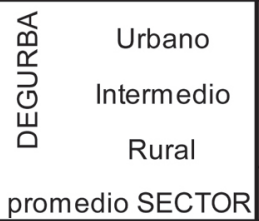 } & 16.30 & 13.21 & 15.67 & 14.93 & 16.72 & 15.85 \\
\hline & 17.60 & 10.70 & 15.35 & 16.30 & 19.67 & 16.81 \\
\hline & 17.02 & 11.99 & 14.11 & 21.53 & 16.49 & 16.24 \\
\hline & 17.09 & 11.69 & 15.14 & 17.50 & 17.95 & \\
\hline
\end{tabular}


do habitual en países escandinavos, entre o 20\% e o 25\%, do que en Francia ou España, habitualmente no $35 \%$. Si se aprecia unha maior concesión de crédito no sector da construción, como tamén se desprende dos resultados na literatura. Canto ao financiamento vía provedores, os datos entre o $15 \%$ e $20 \%$ para o caso galego tamén son inferiores aos habituais nos países do sur de Europa.

Canto as variables para diagnosticar as posibles dificultades de acceso a financiamento (Táboa 4), apréciase que o crecemento da débeda é similar entre sectores e concellos de distinto tipo, polo que non semella será unha variable que axude a determinar a

Táboa 4. Acceso a fontes de financiamento e tipoloxía de empresa Promedio 2013-2016, por sector e DEGURBA

\begin{tabular}{|c|c|c|c|c|c|c|c|}
\hline \multirow{2}{*}{\multicolumn{2}{|c|}{ KD }} & \multicolumn{5}{|c|}{ SECTOR } & \multirow{2}{*}{$\begin{array}{l}\text { promedio } \\
\text { DEGURBA }\end{array}$} \\
\hline & & 1 - Alim. & 2 - Textil & 3 - Maquin. & 4 - Constr. & 5 - Enxeñ. & \\
\hline \multirow{3}{*}{ 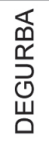 } & Urbano & 1.87 & 3.11 & 3.37 & 3.05 & 3.80 & 3.28 \\
\hline & Intermedio & 3.26 & 3.02 & 2.86 & 2.88 & 3.68 & 3.21 \\
\hline & Rural & 2.52 & 2.94 & 2.87 & 2.68 & 3.20 & 2.91 \\
\hline pror & edio SECTOR & 2.68 & 3.00 & 3.01 & 2.86 & 3.58 & \\
\hline
\end{tabular}

\begin{tabular}{|c|c|c|c|c|c|c|c|}
\hline \multirow{2}{*}{\multicolumn{2}{|c|}{ DGRD }} & \multicolumn{5}{|c|}{ SECTOR } & \multirow{3}{*}{$\begin{array}{c}\text { promedio } \\
\text { DEGURBA } \\
0.30\end{array}$} \\
\hline & & 1 - Alim. & 2 - Textil & 3 - Maquin. & 4 - Constr. & 5 - Enxeñ. & \\
\hline \multirow{3}{*}{ 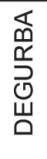 } & Urbano & 0.29 & 0.31 & 0.28 & 0.31 & 0.31 & \\
\hline & Intermedio & 0.30 & 0.30 & 0.28 & 0.24 & 0.29 & 0.28 \\
\hline & Rural & 0.32 & 0.29 & 0.29 & 0.25 & 0.33 & 0.30 \\
\hline pro & edio SECTOR & 0.30 & 0.30 & 0.28 & 0.26 & 0.31 & \\
\hline
\end{tabular}

Tipoloxía

\begin{tabular}{|c|c|c|c|c|c|c|c|}
\hline \multirow{2}{*}{\multicolumn{2}{|c|}{ ASSETS }} & \multicolumn{5}{|c|}{ SECTOR } & \multirow{3}{*}{$\begin{array}{c}\text { promedio } \\
\text { DEGURBA } \\
2894.43\end{array}$} \\
\hline & & 1 - Alim. & 2 - Textil & 3 - Maquin. & 4 - Constr. & 5 - Enxeñ. & \\
\hline \multirow{3}{*}{ 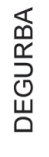 } & Urbano & 977.80 & 3203.75 & 1282.58 & 9608.93 & 1308.40 & \\
\hline & Intermedio & 2513.02 & 3017.25 & 2184.57 & 1338.75 & 1065.14 & 1794.16 \\
\hline & Rural & 1238.17 & 819.31 & 1173.26 & 1082.22 & 1040.11 & 1059.87 \\
\hline \multicolumn{2}{|c|}{ promedio SECTOR } & 1740.78 & 2132.95 & 1685.30 & 3451.03 & 1130.63 & \\
\hline
\end{tabular}

\begin{tabular}{|c|c|c|c|c|c|c|c|}
\hline \multirow{2}{*}{\multicolumn{2}{|c|}{ MARG }} & \multicolumn{5}{|c|}{ SECTOR } & \multirow{2}{*}{$\begin{array}{c}\text { promedio } \\
\text { DEGURBA }\end{array}$} \\
\hline & & 1-Alim. & 2 - Textil & 3-Maquin. & 4 - Constr. & 5 - Enxeñ. & \\
\hline \multirow{3}{*}{ 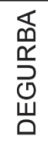 } & Urbano & -2.89 & -2.02 & 1.42 & -1.21 & 0.71 & -0.06 \\
\hline & Intermedio & 3.30 & -0.32 & 1.76 & -0.67 & 1.98 & 1.33 \\
\hline \multirow{2}{*}{\multicolumn{2}{|c|}{ promedio SECTOR }} & 2.11 & 1.82 & 0.51 & 1.63 & 1.77 & 1.55 \\
\hline & & 1.39 & 0.30 & 1.37 & -0.15 & 1.54 & 1.03 \\
\hline
\end{tabular}

Fonte: Elaboración propia 
distinta política comercial dunhas empresas e outras. Sorprende máis a análise descritiva respecto ao custo da débeda: as empresas do rural fináncianse a un custo lixeiramente inferior aos dos outros concellos. Non é unha diferenza elevada, aínda que si recorrente (todos os sectores agás alimentación) e contrario ao esperado. A explicación pode vir da tipoloxía de empresas coas que contamos na mostra, xa que hai diferenzas notables por tamaño e marxe operativa (rendibilidade). Por unha banda, as empresas industriais no rural son notablemente máis pequenas, principalmente no sector téxtil, e as urbanas moito maiores no sector da construción. A priori isto suporía un maior custo da débeda para as empresas pequenas, polo que a diferenza o atopamos na rendibilidade: as empresas sitas en concellos urbanos, e máis en particular as dos sectores alimentación e téxtil, amosaron nos anos da mostra unha rendibilidade negativa, moi inferior á de empresas noutros concellos e sectores.

Con todo, a explicación última é que estamos a empregar unha definición ampla de gastos financeiros. Conforme á normativa contable, os gastos financeiros poden incluír máis conceptos que xuros por débedas con entidades financeiras, como xuros por desconto de efectos comerciais a cobrar, así como as perdas por deterioro do valor da débeda, de instrumentos financeiros, diferenzas negativas de cambio, e outras. É posible, por tanto, que haxa empresas ás que lles afecten diferenzas de cambio ou perdas en débeda cotizada, menos habituais en empresas pequenas.

Na Figura 2 podemos comprobar a relación do custo da débeda coas variables crédito comercial concedido e recibido, crecemento da cifra de negocio e marxe operativa. A tipoloxía urbana (1), intermedia (2) ou rural (3) do concello onde opera a empresa indícase en distinta cor. Por unha banda, a relación do custo da débeda - crédito comercial semella coherente (en particular, para RECS): canto máis caro é o custo de financiarse, menos crédito conceden aos seus clientes. Por outra, entre os posibles determinantes de $\mathrm{KD}$, o crecemento das vendas ten unha relación coherente: as empresas que máis medran son as que conseguen financiamento máis accesible. Porén, non hai un patrón recoñecible para a marxe de beneficios do negocio, pola elevada presencia de casos anómalos (rendibilidades por baixo do $-50 \%$, por exemplo).

Esta será, por tanto, unha limitación dos resultados econométricos na Sección 5. Con todo, a especificación do modelo incluíndo regresores que recollan as diferenzas de marxe, tamaño, crecemento das vendas, etc., debe axudar a discriminar en que medida o carácter rural ou urbano do medio onde operan as empresas implicou realmente un maior uso ou concesión de crédito comercial. Na Táboa 5 recóllense as principais diferenzas rural-urbano para as variables de estudo mediante tests ANOVA de un factor, así como os para comparar especificamente as variables das empresas de concellos rurais contra as das empresas nas tres cidades da provincia (test de Levene de igualdade de varianzas e t-Test para igualdade de medias). 


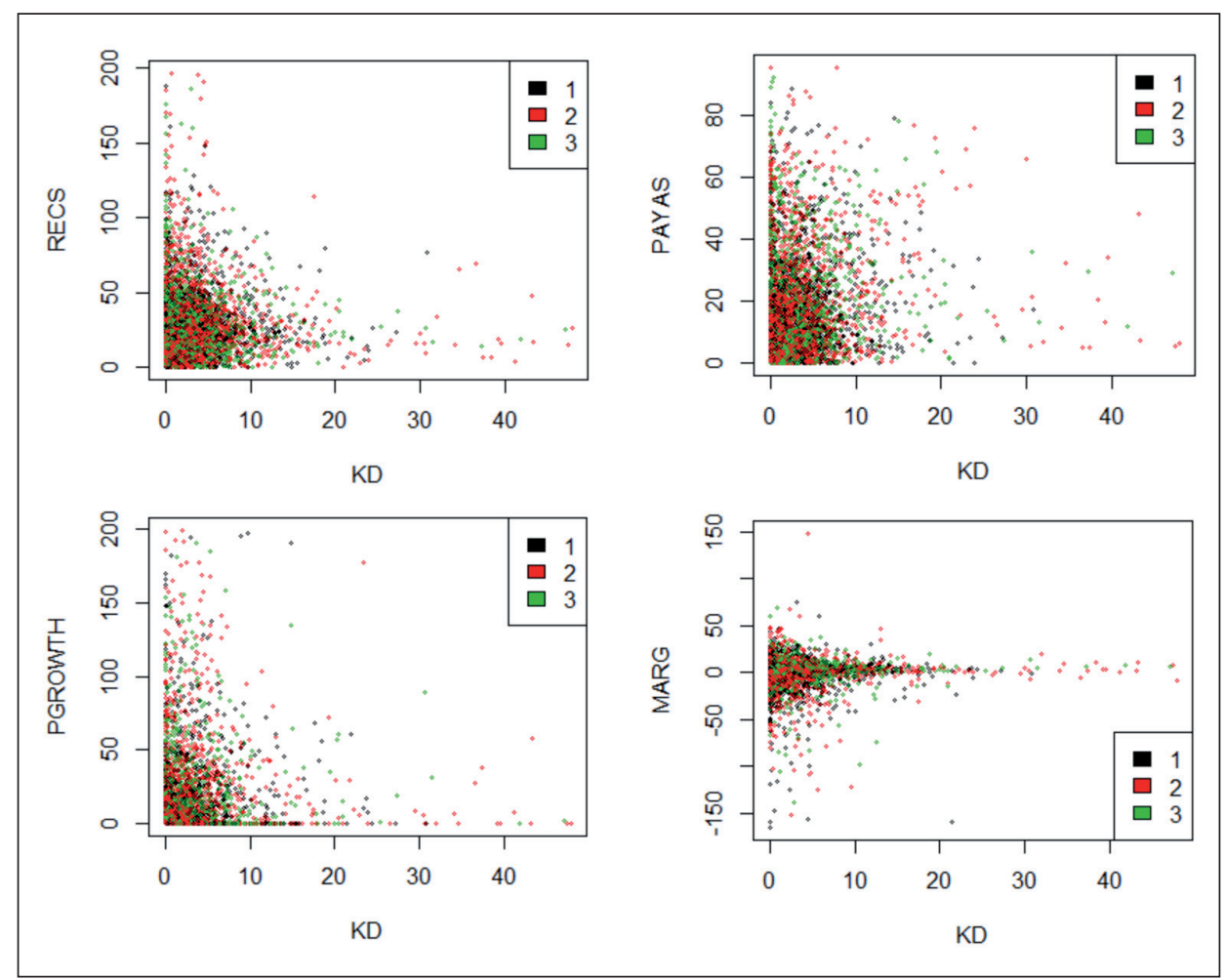

Figura 2. Gráficas de dispersión para o custo da débeda (KD)

Fonte: Elaboración propia

Como se indica, as diferenzas de medias entre os DEGURBA urbano, intermedio e rural son estatisticamente significativas para as contas a cobrar pero non para o crédito comercial recibido, e en canto aos regresores, para a idade, tamaño e ingresos, autofinanciamento, custo da débeda, crecemento das vendas cando son negativas, marxe, rendibilidade, e proporción de activos correntes sobre activos. Ademais, a comparativa entre concellos urbanos vs. rurais apunta que as diferenzas son significativas en todas as devanditas variables agás ROE. 
Táboa 5. ANOVA de un factor: DEGURBA

\begin{tabular}{|c|c|c|c|c|c|c|c|}
\hline & \multicolumn{3}{|c|}{ ANOVA } & \multicolumn{4}{|c|}{ urbano (1) vs. rural (3) } \\
\hline & $\mathrm{F}$ & Sig. & & $\mathrm{F}_{\text {(Test Levene) }}$ & Sig. & $\mathrm{t}$-Test & Sig. \\
\hline RECS & 4.951 & 0.007 & significativa & 1.108 & 0.293 & 3.154 & 0.002 \\
\hline PAYAS & 1.396 & 0.248 & & 2.279 & 0.131 & -0.611 & 0.542 \\
\hline AGE & 34.542 & 0.000 & significativa & 81.773 & 0.000 & 7.613 & 0.000 \\
\hline ASSETS & 26.532 & 0.000 & significativa & 78.127 & 0.000 & 5.591 & 0.000 \\
\hline REVEN & 20.877 & 0.000 & significativa & 18.561 & 0.000 & 3.848 & 0.000 \\
\hline INTFINS & 11.209 & 0.000 & significativa & 35.453 & 0.000 & -4.359 & 0.000 \\
\hline INTFINA & 3.700 & 0.025 & significativa & 3.478 & 0.062 & -2.353 & 0.019 \\
\hline KD & 2.617 & 0.073 & significativa & 0.633 & 0.426 & 2.298 & 0.022 \\
\hline DGRD & 1.005 & 0.366 & & 0.007 & 0.934 & 0.041 & 0.967 \\
\hline PGROWTH & 0.385 & 0.680 & & 0.064 & 0.800 & -0.271 & 0.786 \\
\hline NGROWTH & 3.371 & 0.034 & significativa & 15.010 & 0.000 & -2.361 & 0.018 \\
\hline MARG & 4.653 & 0.010 & significativa & 39.339 & 0.000 & -2.631 & 0.009 \\
\hline ROE & 3.062 & 0.047 & significativa & 7.474 & 0.006 & -0.441 & 0.659 \\
\hline TURN2 & 0.925 & 0.397 & & 0.034 & 0.855 & -1.370 & 0.171 \\
\hline STFINS & 1.160 & 0.313 & & 0.801 & 0.371 & 1.072 & 0.284 \\
\hline STDA & 1.342 & 0.261 & & 0.166 & 0.684 & -0.419 & 0.675 \\
\hline LEVER & 0.775 & 0.461 & & 0.624 & 0.430 & -0.329 & 0.742 \\
\hline CURRAS & 30.871 & 0.000 & significativa & 0.143 & 0.705 & 6.738 & 0.000 \\
\hline
\end{tabular}

Fonte: Elaboración propia

\section{ESPECIFICACIÓN DOS MODELOS. RESULTADOS}

A continuación estímanse dous modelos, un para as contas a cobrar (RECS) e outro para as contas a pagar (PAYAS). A especificación dos modelos realízase conforme a revisión de literatura sobre os determinantes do crédito comercial e variables seleccionadas en consecuencia levada a cabo na Sección 4.2.

\subsection{Especificación dos modelos}

Realízase unha análise estática con datos de panel. As variables RECS e PAYAS estímanse con sendas regresións lineais do tipo

$$
\operatorname{RECS}_{i t}=\beta_{0}+\beta_{i} Z_{i t}+\gamma_{i} D_{i}+\mu_{i}+\lambda_{t}+\varepsilon_{i t}
$$

$\mathrm{e}$

$$
P A Y A S_{i t}=\beta_{0}+\beta_{i} Z_{i t}+\gamma_{i} D_{i}+\mu_{i}+\lambda_{t}+\varepsilon_{i t}
$$

onde $\mathrm{Z}_{\mathrm{it}}$ é o vector de regresores conforme a literatura de determinantes de crédito comercial, e $\mathrm{D}_{\mathrm{i}}$ é un vector que inclúe as dummies rural / urbana (DEGURBAd) - definidas $1=$ 
urbano, 2 = intermedio, 3 = rural - e sectorial $($ SECTd) - unha para cada sector SECT1 a SECT5 antes identificados. Ademais, $\mu_{\mathrm{i}}$ controla os efectos individuais de carácter inobservables, $\lambda_{\mathrm{t}}$ son variables dummy anuais, variables no tempo pero iguais para todos os individuos, e $\varepsilon_{\text {it }}$ é a perturbación aleatoria.

As variables explicativas e impacto previsto sobre a variable explicada en cada regresión son as sinaladas na Sección 4.2., e que se detallan a continuación. Como é habitual tamén na literatura, incluímos entre elas $\mathrm{AGE}^{2}$ e $\mathrm{MARG}^{2}$ para moderar o efecto de valores máis elevados. Deste xeito, no modelo para RECS consideramos as variables (co signo previsto entre paréntese) logASSETS(+), $\operatorname{AGE}(+), \operatorname{AGE}^{2}(+), \operatorname{INTFINA}(+)$, DGRD(+), KD(-), PGROWTH(-/+), NGROWTH(+/-), MARG(+), MARG ${ }^{2}$, TURN2(-), STFINS(+), e ademais comprobamos o posible impacto de ROE(+) e LEVER(+). Canto a PAYAS, as variables son $\log \operatorname{ASSETS}(-), \operatorname{AGE}(-), \operatorname{AGE}^{2}(-), \operatorname{INTFINS}(-), \operatorname{DGRD}(-)$, KD(+), PGROWTH(+), NGROWTH(+), STDA(-), LEVER(-), CURRAS(+), e comprobamos ademais o posible impacto de $\operatorname{ROE}(-)$ e $\operatorname{RECD}(-)$.

As hipóteses principais a testar identificarán as diferenzas para empresas operando en concellos rurais a respecto da concesión e recepción de crédito comercial. En termos da dicotomía rural/urbana, unha evidencia do peor acceso ao crédito en zonas rurais sería que as empresas destes entornas se financiaran, ceteris paribus, en maior medida vía acredores comerciais (o que implica un coeficiente positivo para as dummies DEGURBA_intermedio e DEGURBA_rural no modelo explicativo para PAYAS). En consecuencia, comprobaríamos se quen actúa de financiadores dese crédito comercial son tamén as empresas dos propios concellos rurais (có que identificaríamos sendos coeficientes positivos no modelo para RECS), ou non.

\subsection{Resultados}

Nos modelos de datos de panel nos que regresores invariantes no tempo, como as dummies rural (DEGURBAd) e sectorial (SECTd), son de particular interese, o estimador de efectos fixos non resulta de utilidade - xa que emprega en efecto a variabilidade dos datos no tempo. Por tanto, a alternativa básica que empregaremos é a estimación de efectos aleatorios. Deste xeito, no que se refire ás contas a cobrar, o modelo por efectos aleatorios que inclúe só as dummies rural/urbana apunta un impacto significativo negativo -isto é, as empresas de concellos rurais conceden $2.6 \%$ menos crédito comercial sobre vendas, ceteris paribus, que as empresas urbanas. Porén, ao introducir as dummies sectoriais e temporais (Táboa 6) a diferenza débese substancialmente á composición sectorial das empresas no rural: o coeficiente das dummies DEGURBA intermedio e rural seguen sendo negativas, pero deixan de ser estatisticamente significativas. En particular, apréciase claramente a maior concesión de crédito comercial nos sectores de maquinaria, construción e enxeñería -un $12 \%$ a $14 \%$ das vendas con respecto ao de alimentación. 
Táboa 6. Determinantes das contas a cobrar (RECS)

\begin{tabular}{|c|c|c|c|c|c|c|}
\hline \multicolumn{4}{|c|}{ Random effects GLS regression } & \multicolumn{2}{|c|}{ Number of obs } & 3733 \\
\hline \multicolumn{4}{|c|}{ Group variable: id } & \multicolumn{2}{|c|}{ Number of groups } & 1017 \\
\hline \multirow[t]{4}{*}{ R-sq: } & \multicolumn{3}{|l|}{$=0.2534$} & \multicolumn{2}{|c|}{ Obs per group: mi $n$} & 1 \\
\hline & \multicolumn{3}{|l|}{$=0.2192$} & \multicolumn{2}{|r|}{$\operatorname{avg}=$} & 3.7 \\
\hline & \multicolumn{3}{|l|}{$=0.2124$} & \multicolumn{3}{|c|}{$\max =$} \\
\hline & & & & $W a \mid d c$ & $2(21)$ & 585.06 \\
\hline \multirow[t]{3}{*}{$\operatorname{corr}\left(u_{-} i, X\right)$} & $=0$ (assume & & & Prob > & hi 2 & 0.0000 \\
\hline & \multicolumn{6}{|c|}{ (Std. Err. adjusted for 1017 clusters in id) } \\
\hline & \multicolumn{3}{|c|}{ Robust } & & & \\
\hline RECS & Coef. & Std. Err. & $z$ & $P>|z|$ & [ $95 \%$ Conf & |nterval] \\
\hline I nASSETS & 5. 103656 & .5373987 & 9.50 & 0.000 & 4.050374 & 6. 156938 \\
\hline AGE & -.12039 & .186257 & -0.65 & 0.518 & -.485447 & .244667 \\
\hline AGEsq & .0016023 & .0040561 & 0.40 & 0.693 & -.0063476 & .0095522 \\
\hline I NTFI NA & -.0147791 & .0338729 & -0.44 & 0.663 & -.0811688 & .0516106 \\
\hline DGRD & .9919792 & .4442091 & 2.23 & 0.026 & .1213453 & 1.862613 \\
\hline$K D$ & -.1480103 & .0569395 & -2.60 & 0.009 & -.2596096 & -.0364111 \\
\hline PGROWTH & -.0122229 & .0083926 & -1.46 & 0.145 & -.028672 & .0042262 \\
\hline NGROWTH & -.1250677 & .0247094 & -5.06 & 0.000 & -.1734972 & -.0766382 \\
\hline MARG & .0646757 & .0553801 & 1.17 & 0.243 & -.0438672 & .1732186 \\
\hline MARGs q & -.0010811 & .000581 & -1.86 & 0.063 & -.0022198 & .0000576 \\
\hline TURN2 & .0456266 & .0209701 & 2.18 & 0.030 & .004526 & .0867273 \\
\hline STFINS & .2193286 & .0250641 & 8.75 & 0.000 & .1702039 & .2684534 \\
\hline year d3 & -.6601009 & .4344657 & -1.52 & 0.129 & -1.511638 & .1914361 \\
\hline year d4 & -1.680132 & .4875519 & -3.45 & 0.001 & -2.635717 & -.7245482 \\
\hline year d5 & -2.477303 & .5957171 & -4.16 & 0.000 & -3.644887 & -1.309719 \\
\hline SECTd2 & 4. 234729 & 2. 031252 & 2.08 & 0.037 & .2535495 & 8.215909 \\
\hline SECTd3 & 12. 18184 & 1. 528424 & 7.97 & 0.000 & 9.186188 & 15.1775 \\
\hline SECTd4 & 12. 39983 & 1. 929966 & 6.42 & 0.000 & 8.617161 & 16.18249 \\
\hline SECTd5 & 14. 66089 & 1. 350151 & 10.86 & 0.000 & 12.01464 & 17. 30714 \\
\hline DEGURBAd2 & -.6628548 & 1.430883 & -0.46 & 0.643 & -3.467335 & 2. 141625 \\
\hline DEGURBAd3 & -9267472 & 1. 530274 & -0.61 & 0.545 & -3.926028 & 2. 072534 \\
\hline _cons & -23.79972 & 3. 216712 & -7.40 & 0.000 & -30.10436 & -17.49508 \\
\hline si gma_u & 16. 513133 & & & & & \\
\hline si gma_e & 9.9947981 & & & & & \\
\hline rho & .7318801 & (fraction & f varia & ce due & $u_{-} i$ ) & \\
\hline
\end{tabular}

Fonte: Elaboración propia. Estimación por efectos aleatorios 
Resultan estatisticamente significativas e coherentes co previsto na literatura que conceden máis crédito comercial as empresas máis grandes, con menor crecemento (o cal sería indicativo dun enfoque marketing do crédito a clientes, para mellorar as vendas) e canto máis financiamento a curto prazo conseguen (coherente coa teoría da liquidez e o crédito). Tamén resulta coherente coa teoría de discriminación de prezos a relación positiva coa marxe comercial (pero non é un resultado estatisticamente robusto). Canto á capacidade crediticia, os dous proxies empregados resultan significativos: as empresas que incrementan débeda e as que se financian a un custo da débeda inferior, conceden máis crédito comercial aos seus clientes. Os resultados son cualitativamente robustos a empregar a mostra completa con valores extremos.

Canto ao financiamento vía provedores, a Táboa 7 recolle os resultados do modelo de contas a pagar. Neste caso, o sector alimentación é o que recibe máis financiamento dos seus provedores, mentres que sectores como o téxtil financian ata un $6 \%$ menos das súas vendas.

Case todas as variables resultan estatisticamente significativas e coherentes co previsto na literatura: procuran máis financiamento dos seus provedores as empresas máis novas, con menor capacidade de xerar financiamento interno, canto máis necesitan financiar o crecemento das súas vendas, canto menos débeda bancaria a curto prazo e longo prazo empregan (por efecto substitución), e canto maior a liquidez dos seus activos (conforme a xestión das necesidades de capital corrente). Canto á capacidade crediticia, o indicador DGRD de crecemento da débeda non explica o crédito comercial, pero si o custo da débeda, de xeito coherente e significativo: canto maior é o custo de financiarse, máis recorren ao crédito dos provedores. Os resultados son cualitativamente robustos tamén a empregar a mostra con valores extremos.

No que respecta á interpretación rural / urbana, o modelo amosa que as empresas de concellos intermedios e rurais fináncianse máis vía provedores (en torno ao $1.5 \%$ do seu balance) que as empresas urbanas - coherente coa hipótese de que as empresas situadas no rural contan con peor acceso ao crédito. Porén, o efecto non é estatisticamente significativo. Para profundar na interpretación deste resultado, replicamos o modelo discriminando aquelas empresas que pertencen a un grupo empresarial (DB0F $=0$ ) das PEMEs independentes, sen máis empresas no grupo que a empresa en estudo (DB0F = 1). O resultado amosa o distinto comportamento das empresas dun tipo e doutro. Para as que pertencen a un grupo empresarial, o resultado en termos rural / urbano é claramente significativo: as empresas de concellos intermedios e rurais financian vía provedores un $3 \%$ dos seus activos máis que as urbanas. Para as empresas independentes, o resultado é oposto: o significativo é o custo da débeda ao que conseguen financiarse, mais non se aprecian diferenzas entre as empresas rurais ou urbanas. 
Táboa 7. Determinantes das contas a pagar (PAYAS)

\begin{tabular}{|c|c|c|c|c|c|c|}
\hline \multicolumn{4}{|c|}{ Random effects GLS regression } & \multicolumn{2}{|c|}{ Number of obs } & $=\quad 3747$ \\
\hline \multicolumn{4}{|c|}{ Group variable: id } & \multicolumn{2}{|c|}{ Number of groups } & 1018 \\
\hline \multirow{4}{*}{ R-sq: } & $=0.1549$ & & & Obs pe & group: $\min =$ & $=$ \\
\hline & $=0.0905$ & & & & $\operatorname{avg}=$ & 3.7 \\
\hline & $=0.0976$ & & & & $\max =$ & 4 \\
\hline & & & & Wald c & $2(20)$ & 250.25 \\
\hline $\operatorname{corr}\left(u_{-} i, x\right)$ & $=0$ (assume & & & $\operatorname{Prob}>$ & hi 2 & 0.0000 \\
\hline \multicolumn{7}{|c|}{ (Std. Err. adjusted for 1018 clusters in id) } \\
\hline \multicolumn{7}{|c|}{ Robust } \\
\hline PAYAS & Coef. & Std. Err. & $z$ & $P>|z|$ & [ $95 \%$ Conf & . Interval ] \\
\hline I nASSETS & .1934774 & 4023427 & 0.48 & 0.631 & -.5950998 & .9820545 \\
\hline AGE & -.5446826 & .1524615 & -3.57 & 0.000 & -.8435017 & -.2458635 \\
\hline AGEsq & .0062628 & .0033656 & 1.86 & 0.063 & -.0003336 & .0128591 \\
\hline I NTFI NS & -.1229431 & .022595 & -5.44 & 0.000 & -.1672284 & -.0786577 \\
\hline$K D$ & .1088739 & .0491138 & 2.22 & 0.027 & .0126125 & .2051352 \\
\hline PGROWH & .0232269 & .0055925 & 4. 15 & 0.000 & .0122658 & .034188 \\
\hline NGROWH & .0456486 & .0121938 & 3.74 & 0.000 & .0217493 & .069548 \\
\hline STDA & -.1333815 & .0177796 & -7.50 & 0.000 & -.1682288 & -.0985342 \\
\hline LEVER & -1270999 & .0308362 & -4.12 & 0.000 & -.1875377 & -.0666621 \\
\hline CURRAS & .1206683 & .0184572 & 6.54 & 0.000 & .0844928 & .1568438 \\
\hline RECD & .0093418 & .0036412 & 2.57 & 0.010 & .0022053 & .0164783 \\
\hline year d3 & .0041947 & .2645534 & 0.02 & 0.987 & -.5143204 & .5227098 \\
\hline year d4 & .4677768 & .3101477 & 1.51 & 0.131 & -1401015 & 1.075655 \\
\hline yeard5 & .9291657 & .3822159 & 2.43 & 0.015 & .1800364 & 1.678295 \\
\hline SECTd2 & -6.268093 & 1.839579 & -3.41 & 0.001 & -9.873603 & -2.662584 \\
\hline SECTd3 & -3.681304 & 1.693887 & -2.17 & 0.030 & -7.001261 & -.3613469 \\
\hline SECTd4 & -1.960702 & 1.950253 & -1.01 & 0.315 & -5.783127 & 1.861724 \\
\hline SECTd5 & -2.48412 & 1.720197 & -1.44 & 0.149 & -5.855645 & .8874048 \\
\hline DEGURBAd2 & 1. 561891 & 1.073136 & 1.46 & 0.146 & -.5414166 & 3.665198 \\
\hline DEGURBAd3 & 1. 342558 & 1. 189917 & 1.13 & 0.259 & -9896359 & 3.674752 \\
\hline _cons & 19.89305 & 3. 552446 & 5.60 & 0.000 & 12.93039 & 26.85572 \\
\hline sigma_u & 12.927064 & & & & & \\
\hline sigma_e & 5.9794583 & & & & & \\
\hline rho & .82375327 & Ifraction & varia & ice due & $\left.u_{-} i\right)$ & \\
\hline
\end{tabular}

Fonte: Elaboración propia. Estimación por efectos aleatorios 


\section{CONCLUSIÓNS}

Ao obxecto de identificar diferenzas significativas entre empresas rurais e urbanas no acceso a crédito bancario e comercial, analizáronse os principais determinantes do crédito comercial concedido e recibido por unha mostra de empresas industriais no período 2012-2016, mediante a metodoloxía de datos de panel. A análise preliminar amosa que as cifras de concesión e uso de crédito comercial son relativamente baixas para as empresas galegas no contexto europeo, agás no sector da construción. Non se observa un efecto restrición de crédito diferencial para as empresas do rural, mais concédese significativamente menos crédito no rural e non hai diferenzas significativas no crédito recibido. A demografía empresarial rural - urbana é tamén significativamente distinta a nivel idade, tamaño, ingresos, e xeración de recursos propios, entre outros.

Canto ao modelo econométrico, contrastáronse boa parte das predicións teóricas sobre determinantes de crédito comercial. Por unha banda, conceden máis financiamento aos seus clientes as empresas máis grandes, con menor crecemento (indicativo dun enfoque marketing), canto máis crédito bancario a curto e longo prazo conseguen (coherente coa teoría da liquidez e o crédito), e menor sexa o custo da débeda ao que se financian. Por outra, procuran máis financiamento dos seus provedores as empresas máis novas, con menor capacidade de xerar financiamento interno, canto máis necesitan financiar o crecemento das súas vendas, canto menos débeda bancaria a curto e longo prazo empregan (por efecto substitución), e canto maior é o custo de financiarse.

Canto aos efectos diferenciais rural - urbano, as evidencias empíricas son limitadas. Por unha banda, o crédito comercial concedido polas empresas do rural é significativamente menor - un $2.6 \%$ menos crédito comercial sobre vendas - que as urbanas, mais a diferenza débese substancialmente á distinta composición sectorial das empresas no rural. Por outra, as empresas de concellos intermedios e rurais fináncianse máis vía provedores (en torno ao $1.5 \%$ do seu balance) que as urbanas - coherente coa hipótese de que as empresas situadas no rural contan con peor acceso ao crédito - mais o efecto só é estatisticamente significativo para as empresas que pertencen a un grupo empresarial e non para as PEs independentes.

Estes resultados deben ser tomados con especial cautela, por preliminares. Así, o estudo presenta varias limitacións de tipo econométrico e de acceso aos datos financeiros das empresas analizadas. Canto ás limitacións econométricas, a inclusión de sectores e compoñente rural - urbana, invariantes no tempo para os individuos, esixiu a aplicación de estimación por efectos aleatorios como primeira aproximación. Tamén fica pendente de mellora a identificación de posibles problemas de endoxeneidade entre algúns dos regresores e a perturbación aleatoria. Canto ao acceso a datos de tipo financeiro, a principal limitación é non contar con medidas directas de accesibilidade a crédito bancario, como por exemplo o resultado da súa última solicitude de crédito. No noso caso debemos recorrer ao uso de proxies contables para o crecemento da débeda a longo prazo e para o custo da débeda. Máis aínda, cos datos dispoñibles descoñecemos canto do crédito comercial 
recibido polas empresas ten custo ou non, nin en que casos fan uso das facilidades de desconto por pronto pagamento. Isto limita a interpretación dos resultados que se poidan derivar do estudo.

Por último, estas limitacións poderían ter influído tamén na obtención de poucas evidencias do efecto rural - urbano no acceso a crédito bancario tras a crise financeira, e no uso do crédito comercial como substituto. Máis aló desas limitacións, dúas hipóteses poderían xustificar os resultados. Unha interpretación máis favorable á eficiencia do sistema bancario sería considerar que as distancias entre o contexto rural e urbano, nun pequeno país coma Galicia, e en particular coa crecente utilización nos últimos anos das tecnoloxías na relación banca - cliente, poidan non ser pouco relevantes. Unha interpretación oposta sería que o problema foi precisamente bancario, non empresarial: o proceso de reestruturación do mapa bancario e das extintas caixas de aforro foi de tal escala, que o peche da billa do crédito tería sido similar para todo tipo de empresas, con independencia da súa dimensión territorial.

\section{AGRADECEMENTOS}

Os autores agradecen a Xulia Guntín (USC) polas súas proveitosas recomendacións na elaboración deste artigo. 


\section{BIBLIOGRAFÍA}

Barbut, L. (2009). L'évaluation ex post du PDRN: un regard instructif sur le passé pour améliorer l'avenir. Notes et Études Socio-économiques n ${ }^{\circ} 33,7-39$.

Biais, B., Gollier, C. (1997). Trade credit and credit rationing. Review of Financial Studies 10(4), 903-937.

Burkart, M., Ellingsen, T. (2004). In-Kind Finance: A Theory of Trade Credit. The American Economic Review 94(3), 569-590.

Cassia, L., Vismara, S. (2009). Firms' trade credit and the local level of development of the banking system in Europe. Investment Management and Financial Innovations 6(4), 46-58.

Cork (2016). The Cork 2.0 Declaration 2016. Cork 2.0: European Conference on Rural Development, 5th September 2016, Cork. Available at: http://ec.europa.eu/agriculture/events/rural-development-2016_en.htm

Danielson, M.G., Scott, J.A. (2004). Bank loan availability and trade credit demand. Financial Review 39(4), 579-600.

Deloof, M., La Rocca, M. (2014). Local financial development and the trade credit policy of Italian SMEs. Small Business Economics 44, 905-924.

Emery, G. (1987). An optimal financial response to variable demand, Journal of Financial and Quantitative Analysis 22, 209-225.

Fernández, M., Peón, D. (2017). Desafíos dunha sociedade avellentada e en declive: Desequilibrios territoriais e prestación de servizos. Foro Económico de Galicia, Documento 20/2017. Available at http://www.foroeconomicodegalicia.es/informes/ documentos/

Ferris J.S. (1981). A transactions theory of trade credit use. Quarterly Journal of Economics 94, 243-270.

Garcia-Appendini, E., Montoriol-Garriga, J. (2013). Firms as liquidity providers: Evidence from the 2007-2008 financial crisis. Journal of Financial Economics 109(1), 272-291.

García-Teruel, P., Martínez-Solano, P. (2010). Determinants of trade credit: A Comparative study of European SMEs, International Small Business Journal 28(3), 215-233.

García-Teruel, P., Martínez-Solano, P. (2010b). A dynamic perspective on the determinants of accounts payable. Review of Quantitative Finance and Accounting 34(4), 439-457.

Gustafson, C.R. (2005). Rural small business trade credit: A paradox. Agricultural Finance Review 65(1), 45-57.

Harhoff, D., Körting, T. (1998). Lending relationships in Germany - empirical evidence from survey data. Journal of Banking and Finance 22, 1317-53.

Huang, H., Shi, X., Zhang, S. (2011). Counter-cyclical substitution between trade credit and bank credit. Journal of Banking and Finance 35, 1859-78. 
IGE (2016). Clasificación das parroquias e concellos galegos segundo o grao de urbanización (GU 2016). Instituto Galego de Estatística. http://www.ige.eu/estatico/pdfs/ s3/clasificacions/urbanizacion/MetodoloxiaGU2016Concellos.pdf

López Iglesias, E. (2013). A gobernanza e xestión do medio rural galego a comezos do século XXI: Reflexións e propostas para o debate, En R. Rodríguez González (coord.): Galicia, un mundo rural Vivo. UIMP - Concello de Lalín, Pontevedra. 130-147.

McGuinness, G., Hogan, T. (2016). Bank credit and trade credit: Evidence from SMEs over the financial crisis. International Small Business Journal 34(4), 412-445.

Milder, B. (2008). Closing the gap: Reaching the missing middle and rural poor through value chain finance. Enterprise Development and Microfinance 19(4), 301-316.

Morris, J.R. (1976). On the corporate debt maturity strategies. Journal of Finance 31, 29-37.

Ng, C.K., Smith, J.K., Smith, R.L. (1999). Evidence on the Determinants of Credit Terms Used in Interfirm Trade. The Journal of Finance 54(3), 1109-1129.

Niskanen, J., Niskanen, M. (2006). The determinants of corporate trade credit policies in a bank-dominated financial environment: The case of finnish small firms. European Financial Management 12(1), 81-102.

Petersen, M., Rajan, R. (1995). The effect of credit market competition on lending relationships. Quarterly Journal of Economics, 407-33.

Petersen, M.A., Rajan, R.G. (1997). Trade credit: Theories and evidence. Review of Financial Studies 10, 661-691.

Pike, R., Cheng N.S., Cravens K., et al. (2005). Trade credits terms: asymmetric information and price discrimination evidence from three continents. Journal of Business, Finance and Accounting 32, 1197-1236.

Porter, M.E. (1979). How competitive forces shape strategy. Harvard Business Review.

Psillaki, M., Eleftheriou, K. (2015). Trade Credit, Bank Credit, and Flight to Quality: Evidence from French SMEs. Journal of Small Business Management 53(4), 12191240.

Schwartz, R.A. (1974). An economic model of trade credit. Journal of Financial and Quantitative and Financial Analysis 9, 643-657.

Smith, J.K. (1987). Trade credit and informational asymmetry. Journal of Finance 42, 863-872.

Sun, J., Hu, H. (2013). Trade credit and productivity: evidence from China's ethnic areas. Journal of Chinese Economic and Business Studies 11(4), 279-297.

Yano, G., Shiraishi, M. (2011). Efficiency of trade credit finance in China. Comparative Economic Studies 54(1), 203-225. 